\title{
A pilot study of the pharmacokinetics of continuous magnesium infusion in critically ill patients
}

Jian Wen Chan, Fumitaka Yanase, Emily See, Claire McCue, Zhen-Ti Yong, Lachlan J Talbot, Jeremy PM Flanagan and Glenn M Eastwood

Magnesium is vital for numerous biochemical and physiological functions. ${ }^{1}$ In clinical practice, serum magnesium is most commonly measured as total magnesium, ${ }^{2}$ with normal values ranging between $0.7 \mathrm{mmol} / \mathrm{L}$ and $1.0 \mathrm{mmol} / \mathrm{L}^{1}$ Hypomagnesaemia $(<0.7 \mathrm{mmol} / \mathrm{L})$ is a common finding in critically ill patients, may increase the risk of arrhythmias, and is associated with increased mortality. 2,3 Thus, magnesium supplementation in critically ill patients is common. ${ }^{2}$

Variability in current clinical intravenous magnesium therapy is evident by differences in quantity, frequency, and mode of delivery. This variability may be due to previous studies only reporting the pharmacokinetic data in specific groups: children, ${ }^{4-6}$ pregnant women, ${ }^{7,8}$ and cardiac surgery patients. ${ }^{9-11}$ No study, however, has described the pharmacokinetic effects of continuous intravenous magnesium therapy on total serum magnesium levels in critically ill patients receiving mechanical ventilation and vasopressor support. These patients may be at particular risk of arrhythmias, especially atrial fibrillation. ${ }^{12}$ Moreover, previous small single centre controlled studies have shown that continuous magnesium infusion slows down the ventricular response to atrial fibrillation, ${ }^{13}$ increases its conversion to sinus rhythm ${ }^{13}$ and prevents its development in cardiac surgery patients. ${ }^{14}$

Accordingly, we aimed to evaluate the pharmacokinetics of a combined "bolus plus continuous infusion" protocol of intravenous magnesium therapy targeting total serum magnesium levels between $1.5 \mathrm{mmol} / \mathrm{L}$ and $2 \mathrm{mmol} / \mathrm{L}$ in critically ill, mechanically ventilated, vasopressor-dependent patients. We hypothesised that such intervention would be logistically feasible, provide useful pharmacokinetic data, achieve magnesium target levels, and would not lead to an increase in vasopressor therapy.

\section{Methods}

This pharmacokinetic study was approved by Austin Health Human Research Ethics Committee (Reference No. HREC/52758/Austin-2019-177785; ANZCTR.org.au

\begin{abstract}
Objective: The pharmacokinetics and haemodynamic effect of continuous magnesium infusion in non-cardiac intensive care unit (ICU) patients are poorly understood. We aimed to measure serum and urine magnesium levels during bolus and continuous infusion in critically ill adults, compare serum levels with those of a control population, and assess its haemodynamic effect.
\end{abstract}

Design: Pharmacokinetic study.

Setting: A single tertiary adult ICU.

Participants: Mechanically ventilated adults requiring vasopressor support.

Intervention: A $10 \mathrm{mmol}$ bolus of magnesium sulfate followed by $1.5-3 \mathrm{mmol} / \mathrm{h}$ infusion for 24 hours.

Main outcome measures: The primary outcome was the change in total serum magnesium concentration. The main secondary outcome was mean arterial pressure (MAP)adjusted vasopressor dose.

Results: We matched 31 treated patients with 93 controls. Serum total magnesium concentration increased from a median $0.94 \mathrm{mmol} / \mathrm{L}$ (interquartile range [IQR], 0.83$1.10 \mathrm{mmol} / \mathrm{L})$ to $1.38 \mathrm{mmol} / \mathrm{L}(\mathrm{IQR}, 1.25-1.69 \mathrm{mmol} / \mathrm{L}$; $P<0.001)$ and stabilised between a median $1.64 \mathrm{mmol} / \mathrm{L}$ (IQR, 1.38-1.88 mmol/L) at 7 hours and $1.77 \mathrm{mmol} / \mathrm{L}(\mathrm{IQR}$, $1.53-1.85 \mathrm{mmol} / \mathrm{L})$ at 25 hours. This was significantly greater than in the control group $(P<0.001)$. The MAPadjusted vasopressor dose decreased during magnesium infusion $(P<0.001)$.

Conclusion: In critically ill patients, a magnesium sulfate bolus followed by continuous infusion achieved moderately elevated levels of total serum magnesium with a decrease in MAP-adjusted vasopressor dose.

Trial registration number: ACTRN12619000925145. 


\section{ORIGINAL ARTICLES}

Registration No. ACTRN12619000925145). Written consent was provided by the patient's legally responsible person.

\section{Study inclusion criteria}

We aimed to study a convenience sample of 30 adult patients admitted to the intensive care unit (ICU) of the Austin Hospital in Melbourne, Australia.

We included patients who:

- had an existing intra-arterial catheter, a central venous catheter, and an indwelling urinary catheter;

- were mechanically ventilated via an endotracheal tube;

- were receiving vasopressor therapy; and

- had a treating clinician who decided that intravenous magnesium replacement was indicated.

We excluded patients who:

- were admitted to the ICU following cardiac surgery;

- had an allergy to magnesium sulfate or one of its excipients;

- were pregnant;

- were already receiving or had received a continuous intravenous magnesium infusion in the previous 24 hours;

- were currently receiving a muscle relaxant infusion;

- had a serum creatinine concentration of $>200 \mu \mathrm{mol} / \mathrm{L}$; or

- were receiving continuous renal replacement therapy.

Basic demographic data, physiological parameters and information relating to ICU and hospital length of stay were collected.

\section{Control group}

Using the ICU's electronic admissions database, we retrospectively identified a matched cohort of patients admitted to the ICU in the previous year who were intubated and ventilated and were receiving vasopressor support. They formed a control group for the purpose of comparing magnesium levels in the first 24 hours. Each study patient was matched to three control patients based on age, sex, Acute Physiology and Chronic Health Evaluation (APACHE) III score and admission diagnosis category. We used the ICU's electronic medical records to collect information on basic demographic data, physiological and biochemical parameters along with information relating to ICU and hospital length of stay.

\section{Magnesium infusion}

We administered a $10 \mathrm{mmol}$ bolus of magnesium sulfate through a central venous catheter over one hour, followed by a continuous infusion at a rate of between $1.5 \mathrm{mmol} / \mathrm{h}$ and $3 \mathrm{mmol} / \mathrm{h}$ for 24 hours depending on total serum magnesium levels. The infusion was stopped if there were two consecutive total serum magnesium levels over
$2 \mathrm{mmol} / \mathrm{L}$ or if urine output was less than $200 \mathrm{~mL}$ over 6 hours (Figure 1). Blood and spot urine samples were taken immediately before the bolus infusion and at $6,12,18$ and 24 hours after the bolus administration was completed. Blood and urine samples were sent immediately to a central pathology department for processing.

\section{Primary and secondary outcomes}

The primary study outcome was the change in total serum magnesium levels over a 25 -hour period following the commencement of the intervention.

The main secondary outcome was the change in vasopressor dose (in noradrenaline equivalents) ${ }^{13}$ indexed to mean arterial pressure (MAP) over the observation period. Additional outcomes included assessment of the effect of furosemide on magnesium excretion and the comparison of total serum magnesium, sodium and potassium levels with the control population.

The following pharmacokinetic calculations were used:

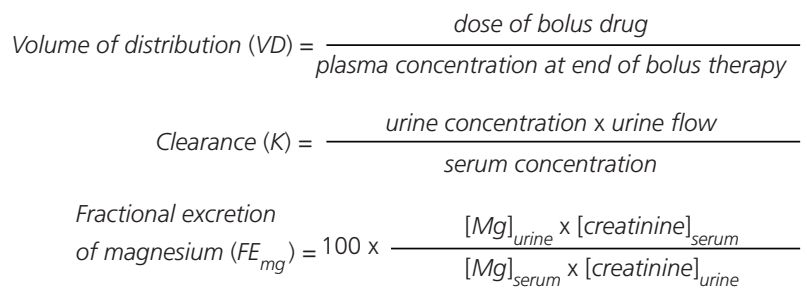

\section{Statistical methods}

Statistical analyses were performed using $R$ v3.5.2 ( $R$ Foundation for Statistical Computing, Vienna, Austria). Continuous variables were expressed as median with interquartile range (IQR) and categorical variables were expressed as $n(\%)$. Baseline variables were compared using the Mann-Whitney $U$ test or Fisher exact test. To compare the difference of magnesium or vasopressors between baseline and each time point, we used a mixed effect model to analyse the time course of each variable, accounting for repeated measurements and treating time as a continuous variable. When time was statistically significant, we performed a post hoc analysis to compare the variables at each time point using a mixed effect model, accounting for repeated measurements and treating time as a categorical variable, adjusted with Tukey test. To compare the intervention group and matched control group at 25 hours, we used the Mann-Whitney $U$ test. For sensitivity analysis, we separated patients into a furosemide use group and a non-furosemide use group during magnesium infusion and applied a mixed effect model. When a group effect or interaction was significant, we compared each time point between the two groups, adjusted with Tukey test. We estimated that a cohort of 30 patients would have a greater than $90 \%$ chance of detecting a change from an estimated 
Figure 1. Magnesium (Mg) supplementation algorithm

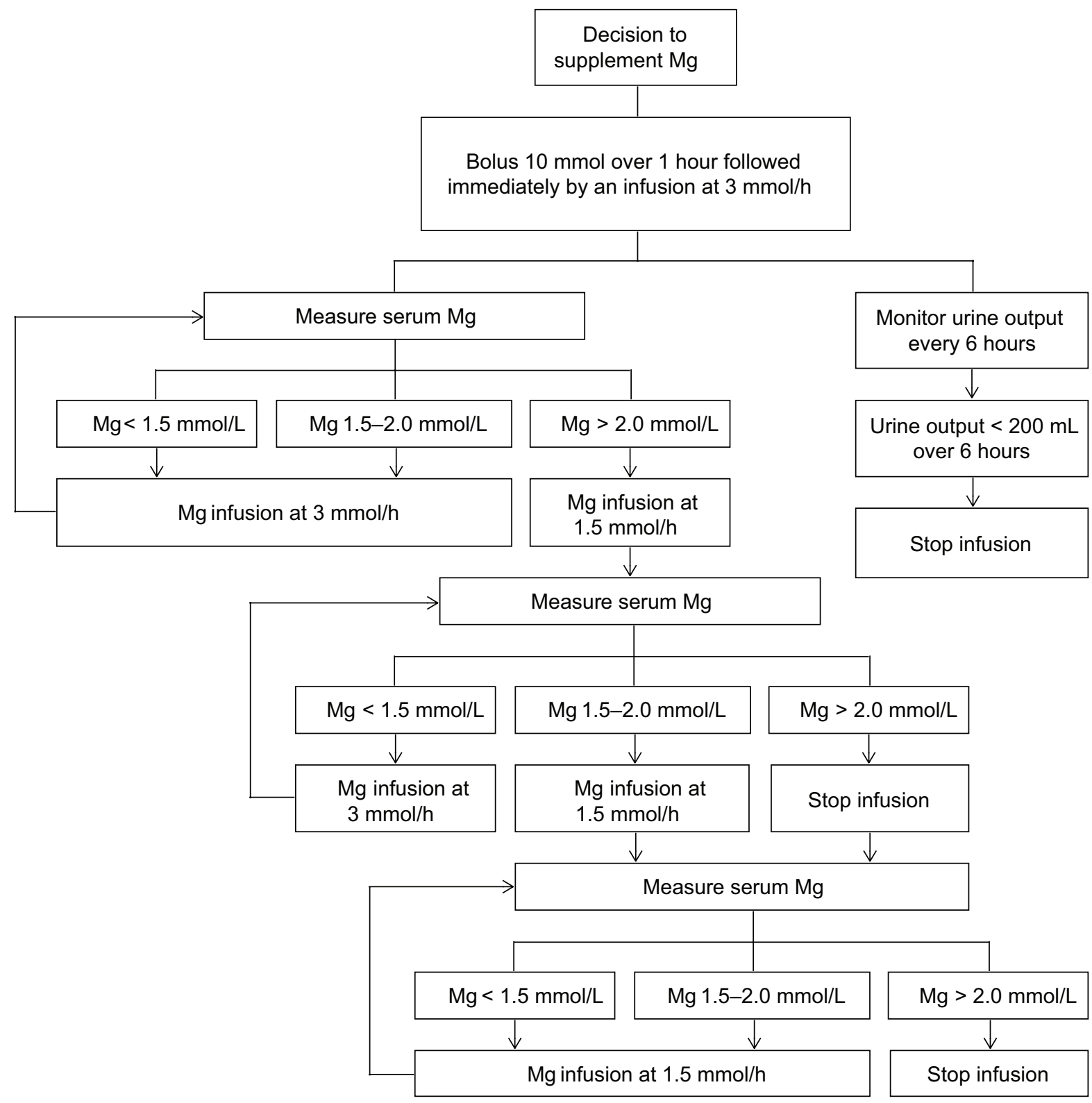

Measure serum and urine $\mathrm{Mg}$ at the following times:

- Immediately before the bolus infusion $(t=0 \mathrm{~h})$

- Immediately after end of bolus infusion $(t=1 \mathrm{~h})$

- 6 hours after end of bolus infusion $(t=7 \mathrm{~h})$

- 12 hours after end of bolus infusion $(t=13 \mathrm{~h})$

- 18 hours after end of bolus infusion $(t=19 \mathrm{~h})$

- 24 hours after end of bolus infusion ( $t=25 \mathrm{~h}$ )

Only alter the rate of infusion once results are available 


\section{ORIGINAL ARTICLES}

baseline total serum magnesium levels from $0.9 \mathrm{mmol} / \mathrm{L}$ to a value of $1.4 \mathrm{mmol} / \mathrm{L}$ (with a standard deviation of $0.65 \mathrm{mmol} / \mathrm{L}$ in both groups) at $\alpha=0.05$. A two-sided $P$ value below 0.05 was considered statistically significant.

\section{Results}

\section{Patients and intervention characteristics}

There were 1442 patients admitted to the study centre between 16 July 2019 and 13 March 2020, of which 31 patients were studied (Figure 2). Ninety-three matched patients from the ICU database were identified to form the control group. The baseline characteristics of the control and intervention groups are outlined in Table 1. During the study period, apart from the intervention, no doses of either enteral or parenteral magnesium sulfate were administered to patients in the intervention group. Historical control group patients received a median of $10 \mathrm{mmol}$ (IQR, $0-20 \mathrm{mmol}$ ) magnesium sulfate intravenously during the first 24 hours in the ICU.

In the intervention group, the median baseline creatinine was $74 \mu \mathrm{mol} / \mathrm{L}$ (IQR, 59-117 $\mu \mathrm{mol} / \mathrm{L})$. One patient (3\%) required a dose reduction, while five (16\%) patients had the magnesium infusion ceased - three patients due to consecutive total serum magnesium concentrations greater than $2.0 \mathrm{mmol} / \mathrm{L}$ and two due to low urine output. No infusions were ceased due to clinical concern.

\section{Effects on total serum magnesium}

At baseline, total serum magnesium concentration was $0.85 \mathrm{mmol} / \mathrm{L}$ in the control group compared with $0.94 \mathrm{mmol} / \mathrm{L}$ in the intervention group $(P=0.029)$ (Table 1).

In the intervention group, total serum magnesium concentration increased from baseline to $1.38 \mathrm{mmol} / \mathrm{L}$ after a $10 \mathrm{mmol}$ bolus of magnesium sulfate administered over one hour, implying a median volume of distribution of $21.28 \mathrm{~L}$ or $0.3 \mathrm{~L} / \mathrm{kg}$. Thereafter, total serum magnesium concentration increased further to $1.64 \mathrm{mmol} / \mathrm{L} 7$ hours after the start of the intervention and remained stable up to 25 hours when it reached $1.77 \mathrm{mmol} / \mathrm{L}(P<0.001)$ (Figure 3, A, and Table 2). There were no instances of total serum magnesium levels greater than $3.0 \mathrm{mmol} / \mathrm{L}$. The corresponding total serum magnesium concentration in the control group, after an equivalent observation period was $0.95 \mathrm{mmol} / \mathrm{L}$, significantly lower than in the intervention group $(P<0.001)$ (Figure 4, A).

\section{Effects on urinary magnesium and clearance}

In the intervention group, urine magnesium concentration increased from a median baseline of $4.2 \mathrm{mmol} / \mathrm{L}$ to $5.5 \mathrm{mmol} / \mathrm{L}$ after the bolus dose. Thereafter, urine magnesium concentrations continually increased to a peak of $29.0 \mathrm{mmol} / \mathrm{L}$ at 19 hours after the start of the intervention $(P<0.001)$ (Figure 3, B, and Table 2).

The median magnesium clearance $\left(\mathrm{K}_{\mathrm{Mg}}\right)$ was $4.14 \mathrm{~mL}$ min at baseline, and increased to a peak of $20.98 \mathrm{~mL} / \mathrm{min}$ at 25 hours after the start of the intervention $(P<0.001)$. The fractional excretion of magnesium $\left(\mathrm{FE}_{\mathrm{Mg}}\right)$ followed a similar trend $(P<0.001)$ (Figure 3, C).

- 798 patients were not receiving vasopressor therapy

- 803 patients were not receiving invasive mechanical ventilation

- 3 patients were aged $<18$ years

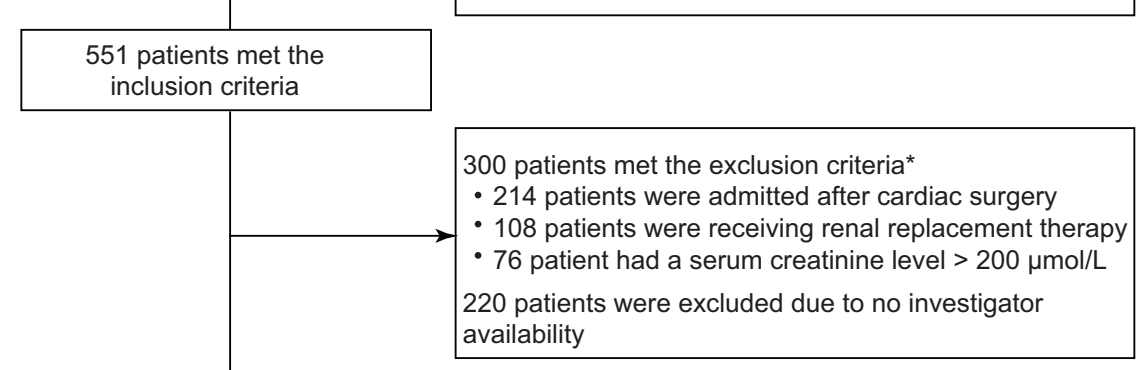

31 patients were included in the analysis

* Categories not mutually exclusive.

\section{Effects on haemodynamic parameters}

There was no statistical difference in heart rate and MAP between the intervention and control groups at baseline or at the end of the intervention period. In the intervention group, over 25 hours, vasopressor requirements (expressed as noradrenaline equivalent doses) decreased from a median of $0.08 \mu \mathrm{g} / \mathrm{kg} / \mathrm{min}$ to $0.00 \mu \mathrm{g} / \mathrm{kg} / \mathrm{min}(P<0.001)$. Similarly, when the noradrenaline equivalent dose was indexed to 
Table 1. Baseline characteristics of study patients

\begin{tabular}{|c|c|c|c|}
\hline & Control & Intervention & $P$ \\
\hline Total number of patients & 93 & 31 & \\
\hline \multicolumn{4}{|l|}{ Demographic characteristics } \\
\hline Age (years), median (IQR) & $60.00(50.00-70.00)$ & $63.04(54.84-74.04)$ & 0.174 \\
\hline Sex, female & $46(49.5 \%)$ & $15(48.4 \%)$ & $>0.99$ \\
\hline Weight (kg), median (IQR) & $75.00(66.50-91.50)$ & $75.00(64.00-85.00)$ & 0.615 \\
\hline \multicolumn{4}{|l|}{ Comorbidities } \\
\hline Hypertension & $28(30.1 \%)$ & $12(38.7 \%)$ & 0.384 \\
\hline Hyperlipidaemia & $14(15.1 \%)$ & $7(22.6 \%)$ & 0.407 \\
\hline Ischaemic heart disease & $12(12.9 \%)$ & $0(0.0 \%)$ & 0.036 \\
\hline Chronic liver disease & $29(31.2 \%)$ & $2(6.5 \%)$ & 0.007 \\
\hline Insulin-dependent diabetes & $5(5.4 \%)$ & $2(6.5 \%)$ & $>0.99$ \\
\hline Paroxysmal atrial fibrillation & $10(10.8 \%)$ & $1(3.2 \%)$ & 0.289 \\
\hline Chronic kidney disease & $7(7.5 \%)$ & $1(3.2 \%)$ & 0.678 \\
\hline \multicolumn{4}{|l|}{ Illness severity } \\
\hline APACHE III, median (IQR) & $59.00(42.00-71.00)$ & $58.00(50.00-78.00)$ & 0.514 \\
\hline \multicolumn{4}{|l|}{ Physiological characteristics } \\
\hline Heart rate, median (IQR) & $80.00(65.00-95.00)$ & $74.00(65.00-85.00)$ & 0.254 \\
\hline Mean arterial pressure $(\mathrm{mmHg})$, median (IQR) & $75.00(70.00-85.00)$ & $75.00(70.00-80.00)$ & 0.945 \\
\hline Central venous pressure $(\mathrm{mmHg})$, median (IQR) & $9.00(7.00-12.00)$ & $10.50(9.50-12.00)$ & 0.251 \\
\hline Sinus rhythm & $93(100.0 \%)$ & $31(100.0 \%)$ & na \\
\hline Respiratory rate, median (IQR) & $15.00(12.00-16.00)$ & $16.00(14.00-19.50)$ & 0.002 \\
\hline $\mathrm{FiO}_{2}$, median (IQR) & $0.40(0.25-0.50)$ & $0.25(0.21-0.38)$ & 0.008 \\
\hline $\mathrm{SaO}_{2}(\%)$, median $(\mathrm{IQR})$ & $98.00(95.00-100.00)$ & $96.00(95.00-98.00)$ & 0.071 \\
\hline \multicolumn{4}{|l|}{ Vasopressor use } \\
\hline Noradrenaline & $85(91.4 \%)$ & $31(100.0 \%)$ & 0.199 \\
\hline Vasopressin & $7(7.5 \%)$ & $3(9.7 \%)$ & 0.71 \\
\hline Adrenaline & $2(2.2 \%)$ & $0(0.0 \%)$ & $>0.99$ \\
\hline Metaraminol & $8(8.6 \%)$ & $0(0.0 \%)$ & 0.199 \\
\hline Ventilation & & & 0.012 \\
\hline Pressure support ventilation & $7(7.5 \%)$ & $8(25.8 \%)$ & \\
\hline SIMV & $86(92.5 \%)$ & $23(74.2 \%)$ & \\
\hline Admission diagnosis category & & & 0.049 \\
\hline Cardiovascular & $1(1.1 \%)$ & $1(3.2 \%)$ & \\
\hline Gastrointestinal & $31(33.3 \%)$ & $6(19.4 \%)$ & \\
\hline Neurological & $28(30.1 \%)$ & $7(22.6 \%)$ & \\
\hline Respiratory & $12(12.9 \%)$ & $3(9.7 \%)$ & \\
\hline Sepsis & $14(15.1 \%)$ & $13(41.9 \%)$ & \\
\hline Trauma & $7(7.5 \%)$ & $1(3.2 \%)$ & \\
\hline \multicolumn{4}{|l|}{ Serum biochemistry } \\
\hline Creatinine $(\mu \mathrm{mol} / \mathrm{L})$, median (IQR) & $76.00(61.75-113.50)$ & $74.00(59.50-117.50)$ & 0.935 \\
\hline Magnesium (mmol/L), median (IQR) & $0.85(0.76-0.96)$ & $0.94(0.84-1.10)$ & 0.029 \\
\hline Sodium (mmol/L), median (IQR) & $139.00(136.00-142.00)$ & $141.00(138.00-143.50)$ & 0.05 \\
\hline Potassium (mmol/L), median (IQR) & $4.20(4.00-4.60)$ & $4.10(4.00-4.45)$ & 0.38 \\
\hline
\end{tabular}

$\mathrm{APACHE}=$ Acute Physiology and Chronic Health Evaluation; $\mathrm{CVP}=$ central venous pressure; $\mathrm{FiO}_{2}=$ fraction of inspired oxygen; IQR = interquartile range; $\mathrm{na}=$ not applicable; $\mathrm{SaO}_{2}=$ oxygen saturations; $\mathrm{SIMV}=$ synchronous intermittent mechanical ventilation. 
MAP, it decreased from a median of $0.001 \mu \mathrm{g} / \mathrm{kg} / \mathrm{min} / \mathrm{mmHg}$ to $0.000 \mu \mathrm{g} / \mathrm{kg} / \mathrm{min} / \mathrm{mmHg}(P<0.001)$ (Figure 3, D, and Table 2).

\section{Effects of furosemide}

In the intervention group, during the study period, 13 patients $(41.9 \%)$ received at least one bolus dose of furosemide, and three patients $(9.7 \%)$ received a furosemide infusion. There were no observed differences in total serum magnesium levels (group effect $P=0.96$; interaction $P=0.54$ ) (Figure $5, A$ ), urine magnesium levels (group effect $P=0.99$; interaction $P=0.19$ ) (Figure $5, \mathrm{~B}$ ) or adjusted vasopressor indexed to MAP (group effect $P=0.29$; interaction $P=0.93$ ) (Figure 5, D) when comparing patients who did and did not

Figure 3. Effects of intervention on (A) total serum magnesium concentrations, (B) urine magnesium concentrations, (C) fractional excretion of magnesium ( $\left(\mathrm{Fe}_{\mathrm{Mg}}\right)$, and $(\mathrm{D})$ adjusted vasopressor dose indexed to mean arterial pressure (MAP)
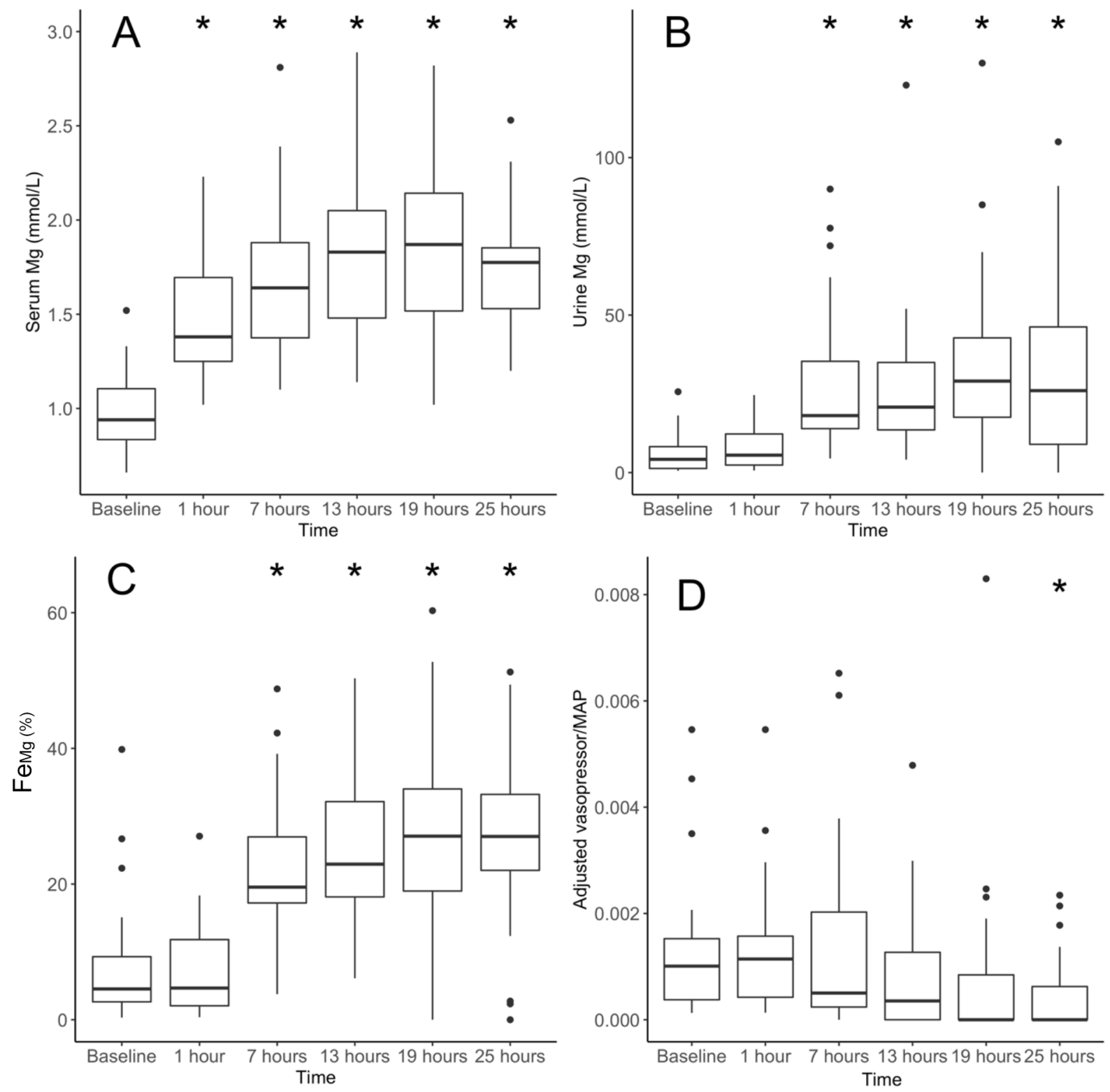

* Signifies statistically significant change to baseline value. 
Table 2. Outcome of magnesium pharmacokinetics and vasopressor requirements expressed as noradrenaline (NAdr) equivalents

\begin{tabular}{|c|c|c|c|c|c|c|c|}
\hline Variable & Baseline & 1 hour & 7 hours & 13 hours & 19 hours & 25 hours & $P$ \\
\hline Serum Mg (mmol/L) & $\begin{array}{c}0.94 \\
(0.83-1.10)\end{array}$ & $\begin{array}{c}1.38 \\
(1.25-1.69)\end{array}$ & $\begin{array}{c}1.64 \\
(1.38-1.88)\end{array}$ & $\begin{array}{c}1.83 \\
(1.48-2.05)\end{array}$ & $\begin{array}{c}1.87(1.52- \\
2.14)\end{array}$ & $\begin{array}{c}1.77 \\
(1.53-1.85)\end{array}$ & $<0.001$ \\
\hline Urine $\mathrm{Mg}(\mathrm{mmol} / \mathrm{L})$ & $\begin{array}{c}4.21 \\
(1.31-8.23)\end{array}$ & $\begin{array}{c}5.53 \\
(2.38-12.25)\end{array}$ & $\begin{array}{c}18.09 \\
(13.95-35.33)\end{array}$ & $\begin{array}{c}20.78 \\
(13.54-34.95)\end{array}$ & $\begin{array}{c}29.04 \\
(17.56-42.76)\end{array}$ & $\begin{array}{c}26.01 \\
(8.97-46.23)\end{array}$ & $<0.001$ \\
\hline Mg clearance (mL/min) & $\begin{array}{c}4.14 \\
(1.61-6.10)\end{array}$ & $\begin{array}{c}4.01 \\
(1.71-9.32)\end{array}$ & $\begin{array}{c}15.45 \\
(7.85-32.04)\end{array}$ & $\begin{array}{c}17.49 \\
(11.09-24.24)\end{array}$ & $\begin{array}{c}17.30 \\
(9.45-28.51)\end{array}$ & $\begin{array}{c}20.98 \\
(10.58-29.69)\end{array}$ & $<0.001$ \\
\hline $\mathrm{Fe}_{\mathrm{Mg}}(\%)$ & $\begin{array}{c}4.54 \\
(2.64-9.30)\end{array}$ & $\begin{array}{c}4.67 \\
(2.05-11.81)\end{array}$ & $\begin{array}{c}19.55 \\
(17.21-26.95)\end{array}$ & $\begin{array}{c}22.93 \\
(18.11-32.15)\end{array}$ & $\begin{array}{c}27.06 \\
(18.97-34.01)\end{array}$ & $\begin{array}{c}27.02 \\
(22.02-33.22)\end{array}$ & $<0.001$ \\
\hline $\begin{array}{l}\text { NAdr equivalence }(\mu \mathrm{g} / \mathrm{kg} / \\
\mathrm{min})\end{array}$ & $\begin{array}{c}0.08 \\
(0.03-0.12)\end{array}$ & $\begin{array}{c}0.08 \\
(0.04-0.11)\end{array}$ & $\begin{array}{l}0.03(0.02- \\
0.15)\end{array}$ & $\begin{array}{l}0.03(0.00- \\
0.08)\end{array}$ & $\begin{array}{l}0.00(0.00- \\
0.07)\end{array}$ & $\begin{array}{c}0.00 \\
(0.00-0.05)\end{array}$ & $<0.001$ \\
\hline $\begin{array}{l}\text { NAdr equivalent dose/MAP } \\
(\mu \mathrm{g} / \mathrm{kg} / \mathrm{min} / \mathrm{mmHg})\end{array}$ & $\begin{array}{c}0.0010 \\
(0.0004- \\
0.0015)\end{array}$ & $\begin{array}{c}0.0011 \\
(0.0004- \\
0.0016)\end{array}$ & $\begin{array}{c}0.0005 \\
(0.0002- \\
0.0020)\end{array}$ & $\begin{array}{c}0.0003 \\
(0.0000- \\
0.0013)\end{array}$ & $\begin{array}{c}0.000 \\
(0.0000- \\
0.0008)\end{array}$ & $\begin{array}{c}0.000 \\
(0.0000- \\
0.0006)\end{array}$ & $<0.001$ \\
\hline Serum Na (mmol/L) & $\begin{array}{c}141 \\
(138-144)\end{array}$ & $\begin{array}{c}141 \\
(138-144)\end{array}$ & $\begin{array}{l}141(137- \\
145)\end{array}$ & $142(138-145)$ & $143(139-147)$ & $144(140-148)$ & $<0.001$ \\
\hline Serum K (mmol/L) & $4.1(4.0-4.5)$ & $4.3(4.0-4.5)$ & $4.1(3.9-4.3)$ & $4.1(4.0-4.3)$ & $4.1(3.8-4.4)$ & $4.0(3.8-4.2)$ & 0.003 \\
\hline Serum creatinine $(\mu \mathrm{mol} / \mathrm{L})$ & $74(60-118)$ & $76(60-119)$ & $75(60-111)$ & $87(59-116)$ & $94(54-110)$ & $80(57-109)$ & 0.947 \\
\hline Urine creatinine $(\mathrm{mmol} / \mathrm{L})$ & $7.7(5.2-11.0)$ & $6.8(4.5-9.9)$ & $5.8(3.5-9.3)$ & $5.8(3.1-7.6)$ & $6.4(2.4-8.5)$ & $5.2(2.9-7.2)$ & 0.014 \\
\hline Urine output (mL/h) & $55(30-80)$ & $50(35-75)$ & $65(40-150)$ & $60(40-120)$ & $55(39-100)$ & $63(40-100)$ & 0.137 \\
\hline
\end{tabular}

receive furosemide. Furosemide therapy, however, increased the $\mathrm{FE}_{\mathrm{Mg}}$ (group effect $P=0.016$ ) (Figure $5, \mathrm{C}$ ).

\section{Effects on serum biochemistry}

In the intervention group, serum sodium concentrations increased from a median $141 \mathrm{mmol} / \mathrm{L}(\mathrm{IQR}, 138-143 \mathrm{mmol} / \mathrm{L}$ ) at baseline to $144 \mathrm{mmol} / \mathrm{L}$ (IQR, 140-148 $\mathrm{mmol} / \mathrm{L}$; $P<0.001)$ over the observation period. The final serum sodium concentration was significantly different from the median control group's serum sodium of $140 \mathrm{mmol} / \mathrm{L}$ (IQR, 137.00-143.00 mmol/L; $P=0.002$ ) (Figure 4, B).

A small statistically significant decrease in serum potassium was noted over the observation period in the intervention group, from a median $4.1 \mathrm{mmol} / \mathrm{L}(\mathrm{IQR}$, $4.0-4.4 \mathrm{mmol} / \mathrm{L})$ to $4.0 \mathrm{mmol} / \mathrm{L}(\mathrm{IQR}, 3.8-4.2 \mathrm{mmol} / \mathrm{L}$; $P=0.003)$. This value was significantly different from the final control group serum potassium median of $4.2 \mathrm{mmol} / \mathrm{L}$ (IQR, 4.0-4.4 mmol/L; $P=0.023$ ) (Figure 4, C). There were no statistically different measurements in serum creatinine levels throughout the observation period (Figure 4, D).

\section{Discussion}

\section{Key findings}

Our study demonstrates that moderate hypermagnesaemia can be safely achieved in mechanically ventilated, vasopressor-dependent critically ill patients with normal to moderately impaired renal function using a "bolus followed by infusion" protocol of magnesium sulfate. In addition, sustained hypermagnesaemia occurred despite a concomitant increase in urinary excretion of magnesium, even when furosemide was given, and resulted in levels that were within target and clearly different from usual care and baseline. Finally, there were no instances of severe hypermagnesaemia (> $3 \mathrm{mmol} / \mathrm{L}$ ) and no increase in vasopressor requirements and only small changes in serum sodium and potassium.

\section{Relationship to previous studies}

To our knowledge, no study had assessed the pharmacokinetics of intravenous magnesium bolus followed by infusion targeting a total serum magnesium level between $1.5 \mathrm{mmol} / \mathrm{L}$ and $2.0 \mathrm{mmol} / \mathrm{L}$ in adult, mechanically ventilated, vasopressor-dependent, critically ill patients. However, in 1995, a study used a magnesium bolus and infusion strategy in patients with atrial tachyarrhythmias. ${ }^{14}$ The investigators delivered a bolus dose of $0.15 \mathrm{mmol} / \mathrm{kg}$ followed by a continuous infusion at $0.1 \mathrm{mmol} / \mathrm{kg} / \mathrm{h}$. This approach increased the probability of conversion to sinus rhythm compared with an amiodarone infusion and similarly targeted serum magnesium concentrations between 
Figure 5. Effect of the intervention grouped by furosemide use on (A) total serum magnesium (Mg) concentrations, (B) urine $\mathrm{Mg}$ concentrations, (C) fractional excretion of $\mathrm{Mg}\left(\mathrm{Fe}_{\mathrm{Mg}}\right)$, and (D) adjusted vasopressor dose indexed to mean arterial pressure (MAP)
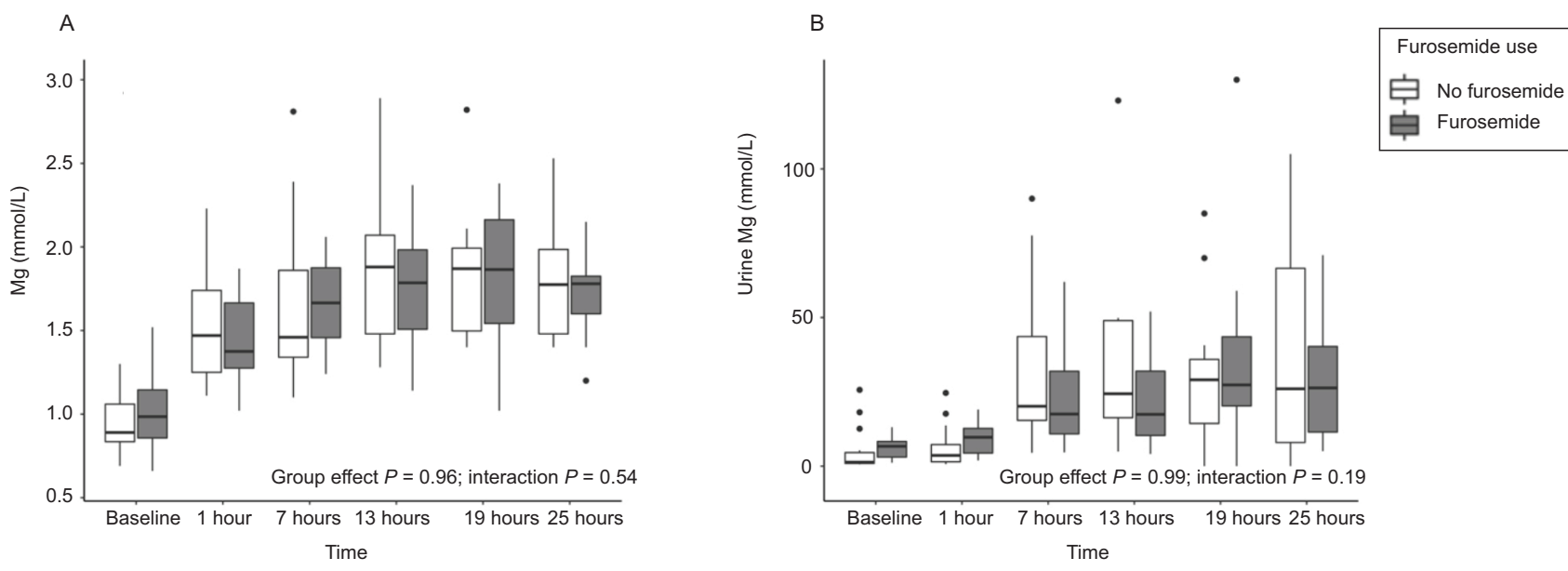

C

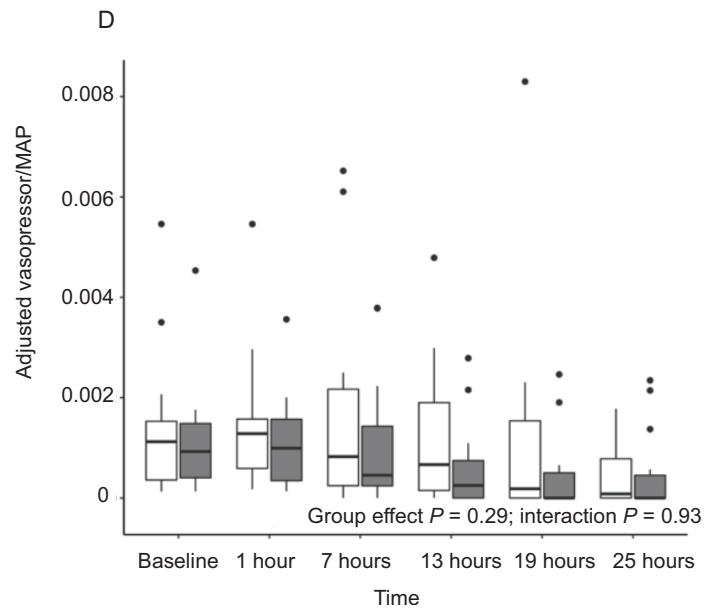

* Signifies statistically significant within group difference.

$1.5 \mathrm{mmol} / \mathrm{L}$ and $2.0 \mathrm{mmol} / \mathrm{L}$ after 24 hours. Regrettably, no pharmacokinetic data such as the volume of distribution or clearance were reported.

With regard to volume of distribution, we found a similar value at $0.3 \mathrm{~L} / \mathrm{kg}$ as seen in patients after cardiac surgery, ${ }^{9-11}$ in women with pre-eclampsia, 7,8 and in children with asthma. 4-6 However, the clearance of magnesium was much greater in pregnant women $(80-100 \mathrm{~mL} / \mathrm{min})$ and children (> $100 \mathrm{~mL} / \mathrm{min}$ ), highlighting that information obtained in relatively healthy individuals cannot be extrapolated to critically ill patients.

Our findings demonstrate that even when the serum creatinine level is normal, in the presence of vasopressor therapy, renal clearance of magnesium is reduced. As a consequence, $20 \%$ of our study population required a reduction in the rate of magnesium infusion, to a greater degree than that seen in cardiac surgery patients. ${ }^{10,11}$ Thus, an increased degree of vigilance in the form of total serum magnesium monitoring is required in patients receiving vasopressor therapy. Similar to previous studies, 2,11 magnesium supplementation did not affect the amount of vasopressor used. Finally, although furosemide increased the urinary excretion of magnesium as previously reported, ${ }^{15-17}$ it did not alter total serum magnesium levels.

\section{Implications of study findings}

Our findings imply that in ICU patients for whom magnesium therapy may be particularly relevant, the volume of distribution is $0.3 \mathrm{~L} / \mathrm{kg}$. Therefore, if the target total serum magnesium level is between $1.5 \mathrm{mmol} / \mathrm{L}$ and $2.0 \mathrm{mmol} / \mathrm{L}$, in a patient weighing $80 \mathrm{~kg}$, assuming a baseline level of $0.8 \mathrm{mmol} / \mathrm{L}$, rapid achievement of such levels would require a bolus dose of about $24 \mathrm{mmol}$ of magnesium sulfate. 
Figure 4. Serum biochemistry of the control and intervention groups, with $P$ values representing statistical significance between the two groups at the end of the intervention period (at 25 hours)

A
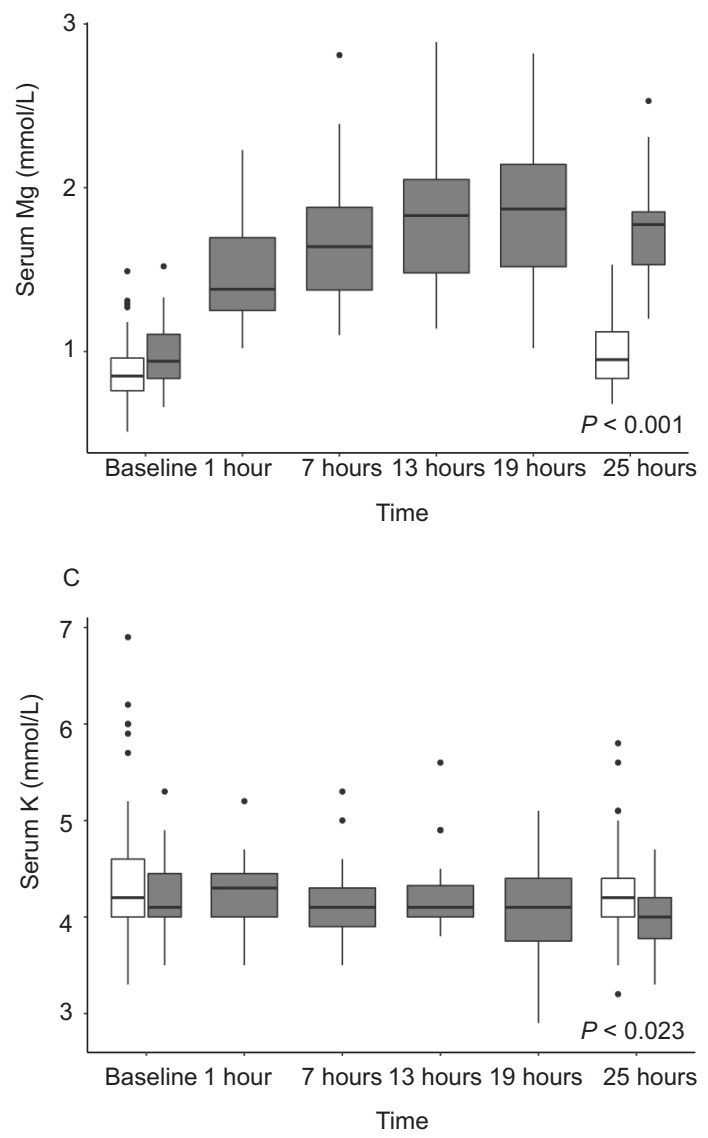

B

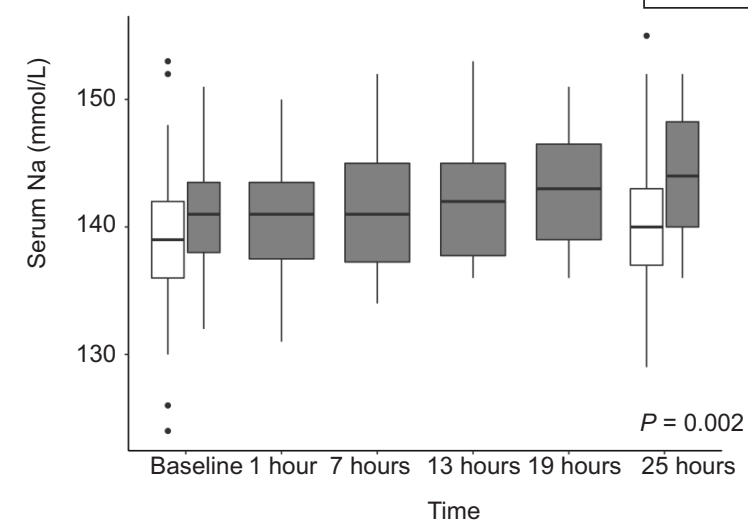

。

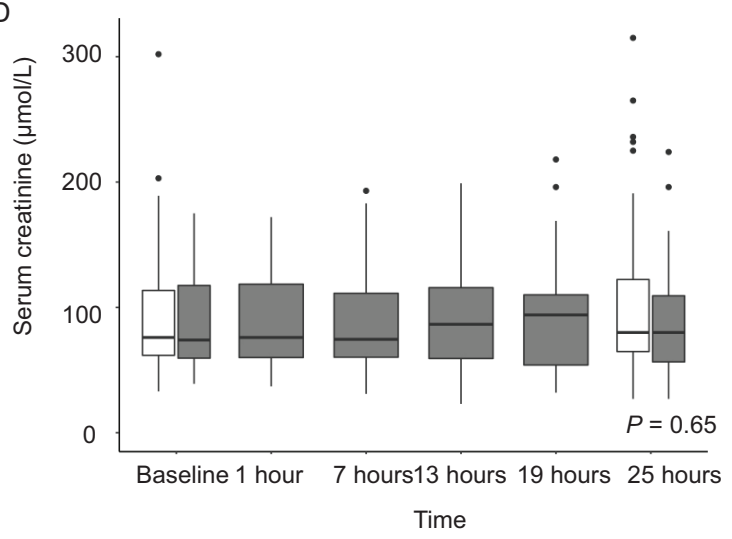

$\mathrm{K}=$ potassium; $\mathrm{Mg}=$ magnesium; $\mathrm{Na}=$ sodium .

Moreover, our findings imply that given the urinary excretion of magnesium in these patients, a continuous infusion of between $1.5 \mathrm{mmol} / \mathrm{h}$ and $3 \mathrm{mmol} / \mathrm{h}$ is necessary to maintain such levels, provided that caution is applied in the presence of oliguria and deteriorating renal function. Furthermore, they imply that such infusion rate is sufficient even in the presence of furosemide treatment. Finally, they imply that the regimen described in this study is likely to be safe, as no deterioration in vasopressor support was noted and no total serum magnesium level exceeded $3.0 \mathrm{mmol} / \mathrm{L}$.

\section{Strengths and limitations}

We report, for the first time, the effect on total serum and urinary magnesium concentrations of a combined bolus and infusion magnesium therapy protocol in noncardiac ICU patients receiving mechanical ventilation and vasopressor therapy. We have provided key pharmacokinetic information, which may help clinicians who wish to target similar magnesium levels in this patient population. We have demonstrated that it is possible to maintain a moderate degree of hypermagnesaemia, that the pharmacokinetics differ somewhat from those seen in relatively healthy patients and are not substantially modified by furosemide therapy.

We acknowledge several limitations. The sample size was small, but doing detailed pharmacokinetics studies is logistically very demanding and expensive. In addition, the design was single centre. However, the findings in the population targeted (vasopressor-dependent, mechanically ventilated patients) are likely to apply to similar such patients in other centres. The duration of the intervention was only 24 hours; therefore, we cannot comment on the clinical risks and benefits of such treatment over longer time periods. However, this study was conducted to inform such 


\section{ORIGINAL ARTICLES}

future prolonged infusion with the goal of affecting clinical outcomes such as atrial tachyarrhythmias.

\section{Conclusion}

In critically ill patients, compared with baseline values and levels in a control population, a magnesium sulfate bolus followed by continuous infusion achieved the target moderately elevated levels of total serum magnesium over 25 hours without ever exceeding a value of $3 \mathrm{mmol} / \mathrm{L}$ and was associated with a decrease in MAP-adjusted vasopressor dose. These findings form the pharmacokinetic basis for future randomised controlled trials of a magnesium infusion targeting moderate hypermagnesaemia in this population with the aim of preventing or slowing atrial fibrillation.

Acknowledgements: This work was supported by the Austin Hospital Anaesthesia Intensive Care Trust Fund.

\section{Competing interests}

All authors declare that they do not have any potential conflict of interest in relation to this manuscript.

\section{Author details}

Jian Wen Chan ${ }^{1}$
Fumitaka Yanase
Emily See $^{1,3,4}$
Claire McCue $^{1}$
Zhen-Ti Yong $^{1}$
Lachlan J Talbot $^{5}$
Jeremy PM Flanagan
Glenn M Eastwood

1 Department of Intensive Care, Austin Hospital, Melbourne, VIC, Australia

2 Australian and New Zealand Intensive Care Research Centre, School of Public Health and Preventive Medicine, Monash University, Melbourne, Australia

3 Department of Nephrology, Royal Melbourne Hospital, Melbourne, Australia

4 Department of Critical Care, The University of Melbourne, Melbourne, Australia

5 Melbourne Medical School, The University of Melbourne, Melbourne, Australia

Correspondence: Jianwen.chan@austin.org.au

doi: https://doi.org/10.51893/2022.1.0A4

\section{References}

1 Jahnen-Dechent W, Ketteler M. Magnesium basics. Clin Kidney J 2012; 5 (Suppl): i3-14.

2 Fairley J, Glassford NJ, Zhang L, Bellomo R. Magnesium status and magnesium therapy in critically ill patients: a systematic review. J Crit Care 2015; 30: 1349-58.

3 Jiang P, Lv Q, Lai T, Xu F. Does hypomagnesemia impact on the outcome of patients admitted to the intensive care unit? A systematic review and meta-analysis. Shock 2017; 47: 288-95.

4 Rower JE, Liu X, Yu T, et al. Clinical pharmacokinetics of magnesium sulfate in the treatment of children with severe acute asthma. Eur J Clin Pharmacol 2017; 73: 325-31.

5 Becker SM, Job KM, Lima K, et al. Prospective study of serum and ionized magnesium pharmacokinetics in the treatment of children with severe acute asthma. Eur J Clin Pharmacol 2019; 75: 59-66.

6 Egelund TA, Wassil SK, Edwards EM, et al. High-dose magnesium sulfate infusion protocol for status asthmaticus: A safety and pharmacokinetics cohort study. Intensive Care Med 2013; 39: 117-22.

7 Brookfield KF, Su F, Elkomy MH, et al. Pharmacokinetics and placental transfer of magnesium sulfate in pregnant women. Am J Obstet Gynecol 2016; 214: 737.e1-9.

8 Okusanya BO, Oladapo OT, Long Q, et al. Clinical pharmacokinetic properties of magnesium sulphate in women with pre-eclampsia and eclampsia. BJOG 2016; 123: 356-66.

9 Biesenbach P, Mårtensson J, Lucchetta L, et al. Pharmacokinetics of magnesium bolus therapy in cardiothoracic surgery. J Cardiothorac Vasc Anesth 2018; 32: 1289-94.

10 Biesenbach P, Mårtensson J, Osawa E, et al. Magnesium supplementation: pharmacokinetics in cardiac surgery patients with normal renal function. J Crit Care 2018; 44: 419-23.

11 Osawa EA, Biesenbach P, Cutuli SL, et al. Magnesium sulfate therapy after cardiac surgery: a before-and-after study comparing strategies involving bolus and continuous infusion. Crit Care Resusc 2018; 20: 209-16.

12 Asfar P, Meziani F, Hamel JF, et al; SEPSISPAM Investigators. High versus low blood-pressure target in patients with septic shock. N Engl J Med 2014; 370: 1583-93.

13 Khanna A, English SW, Wang XS, et al; ATHOS-3 Investigators. Angiotensin II for the treatment of vasodilatory shock. N Engl J Med 2017; 377: 419-30.

14 Moran JL, Gallagher J, Peake SL, et al. Parenteral magnesium sulfate versus amiodarone in the therapy of atrial tachyarrhythmias: a prospective, randomized study. Crit Care Med 1995; 23: 1816-24.

15 Quamme GA. Renal magnesium handling: new insights in understanding old problems. Kidney Int 1997; 52: 1180-95.

16 Quamme GA. Effect of furosemide on calcium and magnesium transport in the rat nephron. Am J Physio/ 1981; 241: F340-7.

17 Dodion L, Ambroes Y, Lameire N. A comparison of the pharmacokinetics and diuretic effects of two loop diuretics, torasemide and furosemide, in normal volunteers. Eur J Clin Pharmacol 1986; 31 (Suppl): 21-7. 